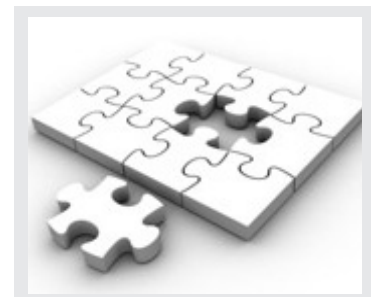

In an effort to facilitate the selection of appropriate peer reviewers for Transformation in Higher Education, we ask that you take a moment to update your electronic portfolio on http:/ / www. thejournal.org.za for our files, allowing us better access to your areas of interest and expertise, in order to match reviewers with submitted manuscripts.

\section{If you would like to} become a reviewer, please visit the journal website and register as a reviewer.

To access your details on the website, you will need to follow these steps:

1. Log into the online journal at http:/ / www. thejournal.org.za

2. In your 'user home' [http://www.thejournal. org.za/index.php/THE/ user] select 'edit my profile' under the heading 'my account' and insert all relevant details, bio statement and reviewing interest/s.

3. It is good practice as a reviewer to update your personal details regularly to ensure contact with you throughout your professional term as reviewer to the Transformation in Higher Education.

Please do not hesitate to contact us if you require assistance in performing this task.

Publisher: publishing@aosis.co.za

Tel: +27 219752602

Fax: +27 219754635

\title{
Transformation in Higher Education
}

The editorial team of Transformation in Higher Education recognises the value and importance of the peer reviewer in the overall publication process - not only in shaping the individual manuscript, but also in shaping the credibility and reputation of our journal.

We are committed to the timely publication of all original, innovative contributions submitted for publication. As such, the identification and selection of reviewers who have expertise and interest in the topics appropriate to each manuscript are essential elements in ensuring a timely, productive peer review process.

We would like to take this opportunity to thank all reviewers who participated in shaping this volume of Transformation in Higher Education:

\author{
A. Becker \\ André Goodrich \\ Annamagriet de Wet \\ Brigitte Smit \\ C. Herman \\ C. Wolhuter \\ Chris Reddy \\ Christo Lombaard \\ Clive Kronenberg \\ Cornelia Roux \\ D. Postma \\ Heid Leganger-Krogstad \\ Ian A. Nell \\ J. Orchard \\ J. Jarvis
}

Josef de Beer

Joseph Divala

Juliet Perumal

K. Maree

Kobus Lombard

L.J. Wood

Merridy Wilson-Strydom

N. Carrim

N. Davids

R. Albertyn

S. Maistry

Stefan Ramaekers

Tilly Moodley

W. Vass

We appreciate the time taken to perform your review/s successfully. 